\title{
"RETROSPECTIVE ANALYSIS OF XPERT MTB/RIF IN IRL KARNATAKA UNDER RNTCP”
}

\author{
Mr.Kanaka Prasad.A MSc \\ Research scholar, Department of Microbiology \\ Marudhapandiar College Vallam \\ Thanjavur,Tamilnadu
}

\author{
Dr.Bharathidasan MSc,MPhil.PhD \\ Associate Professor, Department of Microbiology \\ Marudhapandiar College Vallam \\ Thanjavur,Tamilnadu
}

\begin{abstract}
Background: India is one of the high burden countries for Tuberculosis and accounts for one-fourth of the global case load. The vital challenges faced by the Revised National TB Control Programme (RNTCP) in achieving its objectives are initial default and loss during follow-up.

Objective: Diagnostic delays with MDR-TB usually due to the traditional methods, are associated with adverse clinical outcomes and an increase in transmission of the infection. The Xpert MTB/RIF assay (Cartridge Based Nucleic Acid Amplification Test - CBNAAT), is a new diagnostic device, used to rapidly detect tuberculosis infection and rifampicin resistance. The method now is a part of the widely recommended universal DST by RNTCP, which requires that all clinical samples should be tested first using the CBNAAT. It was hence, decided to assess the performance of Xpert MTB/RIF (CBNAAT) assay for detecting rifampicin resistance against the conventional drug susceptibility testing in liquid culture, using the automated BD MGIT 960 liquid culture system.
\end{abstract}

Materials and Methods: A total of 2500 specimens were included in the assessment. Gene Xpert MTB/RIF (CBNAAT) testing was performed using the version 4 cartridges, following the manufacturer's recommendations. The samples were further processed and cultured in liquid medium using the automated BD MGIT 960 liquid culture system. Following this, the first-line phenotypic DST was performed using the SIRE kit, in the automated BD MGIT 960 (Becton \& Dickinson, USA) according to the recommendations of the manufacturer and the proportion method of drug susceptibility testing using the gold standard of solid culture using the Lowenstein Jensen Solid Culture Medium (LJ medium). A molecular test for detection of drug resistance, Genotype MDR plus Assay (Line Probe Assay LPA) was also performed for the 2500 samples. The results of all the methods were compared and their respective sensitivities and specificities were calculated for comparison.

Keywords - Rifampicin. MDR, Drug resistance, Xpert MTB/RIF assay, CBNAAT, MGIT 960, Universal DST, UDST

\section{INTRODUCTION}

Tuberculosis (TB) constitutes a serious threat to public health in the world, with nearly 10 million new cases and 1.7 million deaths annually Cohen T, et al (2012). The global control of TB and multiple drug resistant TB (MDR-TB) has created an urgent need for timely and effectively diagnostic method Cohen T, et al (2012). MDR-TB, defined as TB caused by mycobacteria that are resistant to at least isoniazid and rifampicin (RIF), is associated with worse clinical outcomes, and its treatment is expensive, lengthy, and complex Zumla A, et al (2012). Diagnostic delays with MDR-TB are associated with worse clinical outcomes and increased transmission Helb D.et al (2012) Accurate and rapid detection of TB, including smear-negative TB and drug resistant-TB, is critical for improving patient outcomes (increased cure and decreased mortality, additional drug resistance, treatment failure, and relapse) and decreasing TB transmission Traditionally, a diagnosis of MDR-TB infection requires mycobacterial culture and phenotypic drug susceptibility testing (DST) Zumla A, et al (2012). These techniques require relatively advanced laboratory capacity, are labor-intensive, and take 1 to 3 months before the results are available Zumla A, et al (2012). In 2011, the World Health Organization recommended the use of rapid molecular genotyping methods for DST at the initial diagnosis of TB ${ }^{[9]}$. RIF inhibits bacterial DNAdependent RNA polymerase; encoded by the RNA polymerase gene $(r p o B)$. Resistance to this drug has mainly been associated with mutations in a limited region of the $r p o B$ gene. RIF resistance may occur alone or in association with resistance to isoniazid and other drugs Van Rie A et al (1999). A molecular diagnostic based on detection of mutations in an 81-base pair region of the $r p o B$ gene have led to the development of rapid molecular assays for RIF resistance, which is frequently used as a marker for MDR-TB. One of these molecular techniques is Xpert MTB/RIF assay (Cepheid, Sunnyvale, CA, USA) which is a rapid, automated, and cartridge-based genotypic test that can simultaneously detect Mycobacterium tuberculosis complex (MTBC) and RIF resistance ${ }^{[11]}$. Compared to conventional diagnosis methods, the Xpert MTB/RIF assay could detect TB and rifampicin- 
resistance in one sputum sample within $2 \mathrm{~h}$ Chakravorty $\mathrm{S}$ et al (2012). Only few studies have stated in their research the sensitivity and specificity of Gene Xpert but after starting of Universal DST(UDST) all over the India under RNTCP we have taken this paper after implementation of UDST by comparing with the phenotypic methods for extrapulmonary cases.

\section{MATERIALS AND METHODS}

\section{1) Clinical samples}

In total, 2500 specimens were included in the study. They originated from patients with suspected TB and were sent for routine mycobacteriology diagnostics between June 2016 and September 2017 at STDC IRL(Intermediate Reference Laboratory) Bengaluru Karnataka .A total of 28 samples (20 respiratory and 8 non-respiratory samples) that were determined as positive for $M$. tuberculosis complex by Xpert MTB/RIF (Cepheid GeneXpert® System, USA) were included in the study.

\section{2) Procedure of Gene Xpert}

Xpert $\mathrm{mtb} /$ rif testing was performed on samples, using version 4 cartridges, according to the manufacturer's recommendations. The xpert assay sample reagent (containing naoh and isopropanol) was added in a 1:2 ratio to the tubes to kill the mycobacteria and liquefy the sample. The mixture was vigorously shaken and allowed to sit for $15 \mathrm{~min}$ before being shaken again and allowed to sit for another $5 \mathrm{~min}$. Finally, 2 $\mathrm{ml}$ was pipetted into the xpert assay cartridge and inserted into the genexpert instrument for polymerase chain reaction (pcr) testing. The measurement and analysis were conducted automatically and reported by the genexpert $\mathrm{dx}$ software (version 4.0).

\section{3) Digestion and Decontamination}

Samples would be processed using the NALC- $\mathrm{NaOH}$ method of homogenization and decontamination. Samples are decontaminated using the $\mathrm{N}$-acetyl - L cystine - sodium hydroxide (NALC $-\mathrm{NaOH}$ ) method.

In a biological safety cabinet, using a sterile, tight fitting screw capped centrifuge tube/universal container, add equal amount of specimen and freshly prepared NALC-NaOH Sodium Citrate Solution. (Approx. 10ml of each). Cap the centrifuge tube and mix using a vortex mixer, until the specimen is liquefied. If the specimen is highly viscous or mucoid, add more NALC powder (approx 35mg) and repeat mixing Allow mixture to stand in room temperature with gentle shaking. Avoid over treating the specimen Make up the PBS to the $50 \mathrm{ml}$ mark on the centrifuge tube and mix well. Centrifuge for 15-20 minutes at 3000g.Carefully decant all supernatant fluid Add small quantity of PBS of $\mathrm{pH} 6.8$ (approx0.5 - 2ml) to resuspend the sediment. Use the sediment for preparation of smears and performance of mycobacterial procedures.

\section{EXPERIMENT AND RESULT}

Genotype MTBDR plus Line probe assay technology involves the following steps:

The Genotype MTBDR plus test is based on the DNA STRIP technology and permits the molecular genetic identification of the M.tuberculosis complex and its resistance to rifampicin or isoniazid from culture isolates or directly from smear positive pulmonary sputum samples. The identification of rifampicin resistance is enabled by the detection of the most significant mutations of the rpo B gene (coding for the beta sub unit of the RNA polumerase). For testing high level of isoniazid resistance, the kat $\mathrm{G}$ gene (coding for the catalase peroxidase) is examined and for testing low level isoniazid resistance.

A. Extraction: DNA is extracted from M.tuberculosis isolates or directly from clinical specimens by using GenoLyse.

Amplification: Amplification of the resistance-determining region of the gene under question is performed using biotinylated primers by the polymerase chain reaction (PCR).

Hybridization: labeled PCR products are hybridized with specific oligonucleotide probes immobilized on a strip. Captured labeled hybrids are detected by colorimetric development, enabling detection of the presence of $\mathbf{M}$. tuberculosis complex, as well as the presence of wild-type and mutation probes for resistance. If a mutation is present in one of the target regions, the amplicon will not hybridize with the relevant probe. Mutations are therefore detected by lack of binding to wild-type probes, as well as by binding to specific probes for the most commonly occurring mutations.

Interpretation: The post-hybridization reaction leads to the development of colored bands on the strip at the site of probe binding and is observed by eye.

\section{1) Cultures and phenotypic DST}

The MTBC culture and first-line phenotypic DST were performed in automated BD MGIT 960 (Becton \& Dickinson, USA) according to the recommendations of the manufacturer.

Specimens were decontaminated using NALC- $\mathrm{NaOH}$ except sterile body fluids like cerebrospinal fluid. After concentration by centrifugation at $3000 \mathrm{~g}$ for $15 \mathrm{~min}$, the sediment was 
resuspended in $1.5 \mathrm{~mL}$ of $0.5 \mathrm{M}$ phosphate buffer $(\mathrm{pH}$ 6.8) and inoculated in MGIT-7H9 broth supplemented with oleic acidalbumin-dextrose-catalase (OADC) and PANTA (Becton Dickinson). This was incubated using MGIT 960 instrument (Becton-Dickinson and Company, Sparks MD, USA) as well as Lowenstein-Jensen (LJ) medium at $37^{\circ} \mathrm{C}$. MTBC strains grown on MGIT medium were tested for drug susceptibility in MGIT 960.

In MGIT 960, according to standard procedures. The drug concentration used was rifampicin $1.0 \mu \mathrm{g} / \mathrm{mL}$. The proportion of resistant organisms in the inoculum was calculated by comparing the number of colonies growing on the drug-free medium (minimum number required $=50$ ) with the number growing on drug-containing medium. If $>1 \%$ of the inoculum was found to grow in the presence of the critical concentration used, the isolate/strain was regarded as drug resistant.

\section{RESULTS}

The clinical utility of all the samples 2500 was seen by comparing with BD MGIT 960, Genotype MDR plus. The Xpert MTB/RIF assay detected Rifampicin resistance in 3 of $28(10.71 \%)$ samples. The resistance was conferred by two different $r p o B$ gene mutations in the $81 \mathrm{bp}-\mathrm{RRDR}$ of MTB. These were detected by probes $\mathrm{D}$ and $\mathrm{E}$. The probe frequency associated with the observed RIF-resistance were as follows: E (2/3), D (1/3) and no RIF-resistance was associated with probe $\mathrm{A}, \mathrm{B}$ and $\mathrm{C}$.

Xpert MTB/Rif, Genotype MTBDR plus, LJ Solid Medium and in MGIT 960 automated system, Rifampicin resistance was detected only in $2 / 28$ isolates (Table 1 ). The isolate that determined as resistant to RIF in Xpert MTB/RIF was found to be susceptible in MGIT 960 automated system, and the same result was found when the sample was tested with DST on LJ Media. The isolate was determined as resistant to streptomycin, isoniazid and susceptible to ethambutol by MGIT 960. The other two isolates which were resistant to RIF both in Xpert MTB/RIF and in MGIT 960 found resistant to streptomycin, isoniazid and ethambutol by MGIT 960 system

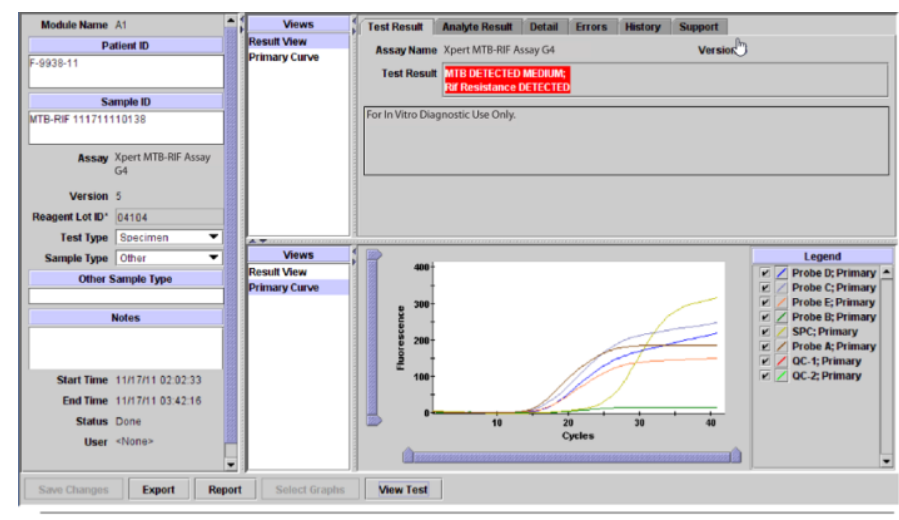

Fig. 1. Rif Resestance case Resust in Gene Expert

Results of rifampicin (RIF) resistance in Xpert MTB/RIF assay, Genotype MTBDRplus, LJ Solid Medium and MGIT 960 system

\section{TABLE 1}

\begin{tabular}{|l|l|l|}
\hline SLNo & Resistant & Susceptible \\
\hline Xpert MTB/RIF & 2 & 26 \\
\hline Genotype & & \\
MTBDRplus & 1 & 27 \\
\hline MGIT 960 & 0 & 28 \\
\hline LJ Medium & 0 & \\
\hline
\end{tabular}

TABLE II

Specimens with rifampicin (RIF) resistance as detected by the Xpert MTB/RIF assay 


\begin{tabular}{|l|l|l|l|}
\hline Specimen & Type & $\begin{array}{l}\text { Basis of } \\
\text { rifampicin } \\
\text { resistance } \\
\text { as detected } \\
\text { by the } \\
\text { MTB/RIF } \\
\text { assay }\end{array}$ & $\begin{array}{l}\text { Rifampicin } \\
\text { phenotypic } \\
\text { susceptibility } \\
\text { result (1.0 } \\
\text { mg/L) }\end{array}$ \\
\hline 1 & $\begin{array}{l}\text { Bronchoalveolar } \\
\text { lavage }\end{array}$ & $\begin{array}{l}\text { Prob E did } \\
\text { not bind }\end{array}$ & R \\
\hline 2 & Gastric fluid & $\begin{array}{l}\text { Prob E did } \\
\text { not bind }\end{array}$ & $\mathrm{R}$ \\
\hline 3 & Sputum & $\begin{array}{l}\text { Prob D did } \\
\text { not bind }\end{array}$ & $\mathrm{S}$ \\
\hline
\end{tabular}

\section{CONCLUSION/DISCUSSION}

Among 2500 specimens included, 2479 samples were of pulmonary and 167 samples were obtained from suspected Extrapulmonary patients. Sensitivity and specificity of Gene Xpert MTB/Rif was assessed by comparing the results with BD MGIT 960 and Genotype MDR plus Assay. Of 2500 samples processed, 28 samples detected the presence of MTB through Gene Xpert MTB/Rif, among which 3 (10.71\%) were Rifampicin resistant. When the same samples subjected to MGIT 960 automated systems, 2 (7.14\%) were resistant and 1 (3.57\%) was found to be sensitive and the same has been found with $\mathrm{LJ}$ proportion method.

This study highlights the efficiency of the Gene expert for RIF after the implementation of UDST giving up front DST by doing Gene Xpert and showed with the respective results of both Genotypic, Phenotypic.

Hence, we would like to conclude that Xpert MTB/RIF assay can be used as first-line assay for the detection of M.tuberculosis but the microbiologists must be aware of the limitations of the assay and the results to be confirmed with the other phenotypic methods.

\section{REFERENCE}

[1] Blakemore R, Story E, Helb D, Kop J, Banada P, Owens MR, et al (2010) Evaluation of the analytical performance of the Xpert MTB/RIF assay. J ClinMicrobiol. ;48(7):2495-2501

[2] Chakravorty S, Kothari H, Aladegbami B, Jin Cho E, Lee JS, Roh SS,( 2012) Rapid, high-throughput detection of rifampicin resistance and heteroresistance in Mycobacterium tuberculosis by use of sloppy molecular beacon melting temperature coding. J ClinMicrobiol; 50(7):2194-2202..

[3] Boehme CC, Nabeta P, Hillemann D, Nicol MP, Shenai S, Krapp F,( 2010) . Rapid molecular detection of tuberculosis and rifampicin resistance. $\mathrm{N}$ Engl $\mathrm{J}$ Med. 363(11):1005-1015. 2010.

[4] . Chang K, Lu W, Wang J, Zhang K, Jia S, Li F,(2012) Rapid and effective diagnosis of tuberculosis and rifampicin resistance with Xpert MTB/RIF assay : a metaanalysis. J Infect. ;64(6):580-588J..

[5] . Cohen T, van Helden PD, Wilson D, Colijn C, McLaughlin MM, Abubakar I ;(2012) Mixedstrain Mycobacterium tuberculosis infections and the implications for tuberculosis treatment and control. ClinMicrobiol Rev; 25(4):708-719.

[6] Falzon D, Jaramillo E, Schünemann HJ, Arentz M, Bauer M, Bayona J,(2011); WHO guidelines for the programmatic management of drug-resistant tuberculosis: 2011 update. EurRespir J. ;38(3):516-528

[7] Durmaz R;(2010); Mycobacterium tuberculosis suşlarindadirencinbelirlenmesindemoleküler yöntemler/son gelişmeler. ANKEM Derg. ;24(2):64-70.

[8] . Glynn JR, Yates MD, Crampin AC, Ngwira BM, Mwaungulu FD, Black GF;(2004); DNA fingerprint changes in tuberculosis: reinfection, evolution, or laboratory error? J Infect Dis.; 190(6):1158-1166.

[9] Helb D, Jones M, Story E, Boehme C, Wallace E, Ho K,;(2010); Rapid detection of Mycobacterium tuberculosis and rifampicin resistance by use of ondemand, near-patient technology. J ClinMicrobiol.; 48(1):229-237. 2010.

[10] Huyen MN, Kremer K, Lan NT, Cobelens FG, Buu TN, Dung NH,;(2012); Mixed tuberculosis infections in rural South Vietnam. J ClinMicrobiol.;50(5):1586-1592

[11] . Mboowa G, Namaganda C, Ssengooba W.(2014); Rifampicin resistance mutations in the 81 bp RRDR of rpoB gene in Mycobacterium tuberculosis clinical isolates using Xpert ${ }^{\circledR}$ MTB/RIF in Kampala, Uganda: a retrospective study. BMC Infect Dis.; 14:481-481.

[12] .OzyurM.(2012);

Akciğerveakciğerdışıtüberküloztanısındamoleküleryönte mlerinkullanımı Mikrobiyol Bul.; 46(3):319-331.

[13] Steingart KR, Schiller I, Horne DJ, Pai M, Boehme CC, Dendukuri N;(2014); Xpert ${ }^{\circledR}$ Mtb/Rif assay for pulmonary tuberculosis and rifampicin resistance in adults. Cochrane Database SystRev. 2014;2014(1):1-166. Telenti A, Imboden P, Marchesi F, Lowrie D, Cole S, Colston MJ, et al. Detection of rifampicin-resistance mutations in Mycobacterium tuberculosis . Lancet. ;341(8846):647650.

[14] . Theron G, Peter J, Van Zyl-Smit R, Mishra G, Streicher E, Murray S,;(2011); . Evaluation of the XpertMTB/RIF assay for the diagnosis of pulmonary tuberculosis in a high HIV prevalence setting. Am J RespirCrit Care Med. ;184:132-140. 
[15] Van Rie A, Warren R, Richardson M, Victor TC, Gie RP, Enarson DA,;(1999); Exogenous reinfection as a cause of recurrent tuberculosis after curative treatment. $\mathrm{N}$ Engl J Med. ; 341:1174-1179.

[16] Yue J, Shi W, Xie J, Li Y, Zeng E.;(2003); Mutations in the rpoB gene of multidrug-resistant Mycobacterium tuberculosis isolates from China 2003. J ClinMicrobiol.; 41(4):2209-2212.

[17] . Zetola NM, Shin SS, Tumedi KA, Moeti K, Ncube R, Nicol M,;(2014); $\quad$ Mixed Mycobacterium tuberculosis complex infections and false-negative results for rifampicin resistance by GeneXpert MTB/RIF are associated with poor clinical outcomes. J ClinMicrobiol.; 52(7):2422-2429.

[18] Zumla A, Abubakar I, Raviglione M, Hoelscher M, Ditiu L, McHugh TD,;(2012); Drug-resistant tuberculosis current dilemmas, unanswered questions, challenges, and priority needs. J Infect Dis.; 20(2):228-240.

[19] . Van Rie A, Mellet K, John MA, Scott L, Page-Shipp L, Dansey H,;(2012); False-positive rifampicin resistance on Xpert MTB/ RIF: case report and clinical implications. Int J Tuberc Lung Dis. ;16(2):206-208. 